\title{
The effect of service climate on customer emotion and customer satisfaction
}

\author{
*Kun-Myong Kang , Ph.D. Student, Dept. of Smart convergence Consulting, Hansung University, KS013 \\ Korea, jangmi1015@naver.com \\ Jung-Wan Hong, Professor, Dept. Of Smart convergence Consulting, Hansung University, KS013 Korea, \\ jwhong@hansung.ac.kr \\ *Corresponding author
}

\begin{abstract}
The purpose of this study is to empirically verify the impact of the effect service climate on customer emotion and customer satisfaction. For this research, a survey was conducted for consultants currently engaged in consulting. Using SmartPLS 3.3.2, technical were conducted. The importance and suitability of the path model were verified through structural model analysis, and the mediating effect of customer emotion was verified through the analysis of specific indirect effects. According to the results of the study, the first company's service climate affects all positive customer emotion: pleasantness, pleasure and happiness. Second, the corporate service climate has a positive effect on customer satisfaction. Third, positive customer sentiment affects customer satisfaction. Fourth, when the service climate of the company affects customer satisfaction, the positive customer emotion, pleasant, enjoyment, and happiness, played a mediating role, and the independent variables were all partially mediated. Among them, happiness appeared to be the most influential factor, showing that it is important to satisfy the customer's happy feelings when the service climate affects customer satisfaction. In order to satisfy customers through research results, establishing and utilizing service climate is important, and since customer's happiness affects service climate and satisfaction, continuous measures to satisfy customer's happiness should be developed. This study is aimed at a small number of restaurant companies, generalizing the results is limited. Nevertheless, it is meaningful to study which of the positive emotions affects a lot by subdividing the customer's feelings when the service climate affects customer satisfaction
\end{abstract}

Keywords: Service Climate, Customer Emotion, Customer Satisfaction, Pleasant, Enjoyment, Happiness Received: 04.12.2020 Accepted: 14.01.2021 $\quad$ Published: 05.02.2021

\section{INTRODUCTION}

As the market environment changes dramatically, competition among companies is becoming fiercer than ever, and this change is expected to continue. One of the key factors that companies should be interested in surviving the market environment is to develop ways to attract customers and maintain a lasting relationship with them[1]. Therefore, many prior studies have confirmed that customer emotion and satisfaction are important factors in continuity. Since it has already been verified that emotions are related to satisfaction[2], this study seeks to explore the effect of service climate on customer emotion and satisfaction of customers using the services provided by the entity. This study focused on the restaurant business. In relation to the restaurant users and the restaurant service providers, we present the service climate as a positive cause of the customer emotion and pay attention to a series of processes that satisfy the customer's satisfaction. The purpose of this study is summarized as follows. First, the entity's service climate provided by restaurant businesses tests how it affects customer emotion. Second, it identifies whether customer emotion affects customer satisfaction. Third, see if the service climate affects customer satisfaction. Fourth, empirically verify the mediated effect of customer emotion on the impact of service climate on customer satisfaction.

\section{Materials and Methods}

\subsection{Literature Review}

\subsubsection{Service climate}

Service climate refers to a recognized organizational culture that employees have in common with respect to the systems, procedures and actions that are rewarded and supported in service contacts [3]. If a company has a passion to improve its services systematically, such as by acting service-oriented to help its customers and rewarding them for high-quality services, employees will perceive it as having a strong service climate[4]. If the company recognizes that customer service provided by the company is 
important among employees, a service climate will be created for the customers.

\subsubsection{Customer emotion}

Customer emotion refers to an emotional and psychological state rather than a perceptual process of information processing that is conscious of the customer's perceived emotional state of the service interface[5]. Looking at the prior studies related to customer feelings in service situations, the customer sentiment study of restaurant customers confirmed that the physical environment of the store has a significant impact on the customer's positive or negative emotion. In particular, it was explained that positive emotions were more influential than negative emotions[6]. This study focused on positive emotions.

\subsubsection{Customer satisfaction}

Customer satisfaction is affected by factors before, during, and after the purchase occurs in connection with the customer's consumption behavior. It also means the difference between the customer's expectations of the service before receiving it and the customer's actual perception after receiving the service[7]. The preceding study found that the customer's cognitive and emotional elements of the product or service are contained, so that if the emotional factors are overlooked, the customer satisfaction cannot be interpreted relatively comprehensively [8]. This study aims to verify the impact of restaurant experience on customer satisfaction due to the service climate.

\subsubsection{Relationship between service climate and customer emotion}

Customer emotions experienced in the service interface are caused by interactions with various environmental factors in the store and have a significant impact on customer behavior [9]. In particular, not only physical factors such as design, scent, and lighting, but also environmental factors such as waiting behavior or 'kindness' of employees can affect customer sentiment. The service climate becomes the company's discriminatory resource and culture created by the company, and customers can recognize the service climate and feel the unique organizational culture that the company has.

\subsubsection{Relationship between customer emotion and Customer satisfaction}

Because customer emotion is directly responsive to the corporate marketing stimuli, it has an important impact on the entire process from customer service purchases[10]. The preceding study argued that the customer's emotional state affects customer satisfaction, and that the customer's positive feelings in the service interface can affect customer satisfaction[11].

\subsubsection{Relationship between service climate and Customer satisfaction}

A study of the service climate from a customer's point of view explained that companies' compensation for employees' service-oriented behavior has a positive impact on customer satisfaction[12]. The service climate in the service sector affects customer attitudes[13]. In order to increase customer satisfaction, employees' attitude toward customers is important. Organizations with a strong service climate increase loyalty while increasing the active attitude and satisfaction of employees as customers and organizations come into contact. Thus, creating a service climate affects employee attitudes and behaviors, and ultimately affects customer satisfaction.

\subsection{Research Model and Hypothesis}

\subsubsection{Research Model}

The basis of the research model was embraced by Service Climate, Customer emotion and Customer Satisfaction. As presented in the preceding study, the Customer Emotion was composed of super variables of Pleasant, Enjoyment and Happiness. In this study, Service Climate was configured as an independent variable, Customer emotion as a parameter, and Customer Satisfaction as a dependent variable. The research model is shown in [Figure 1] below. 


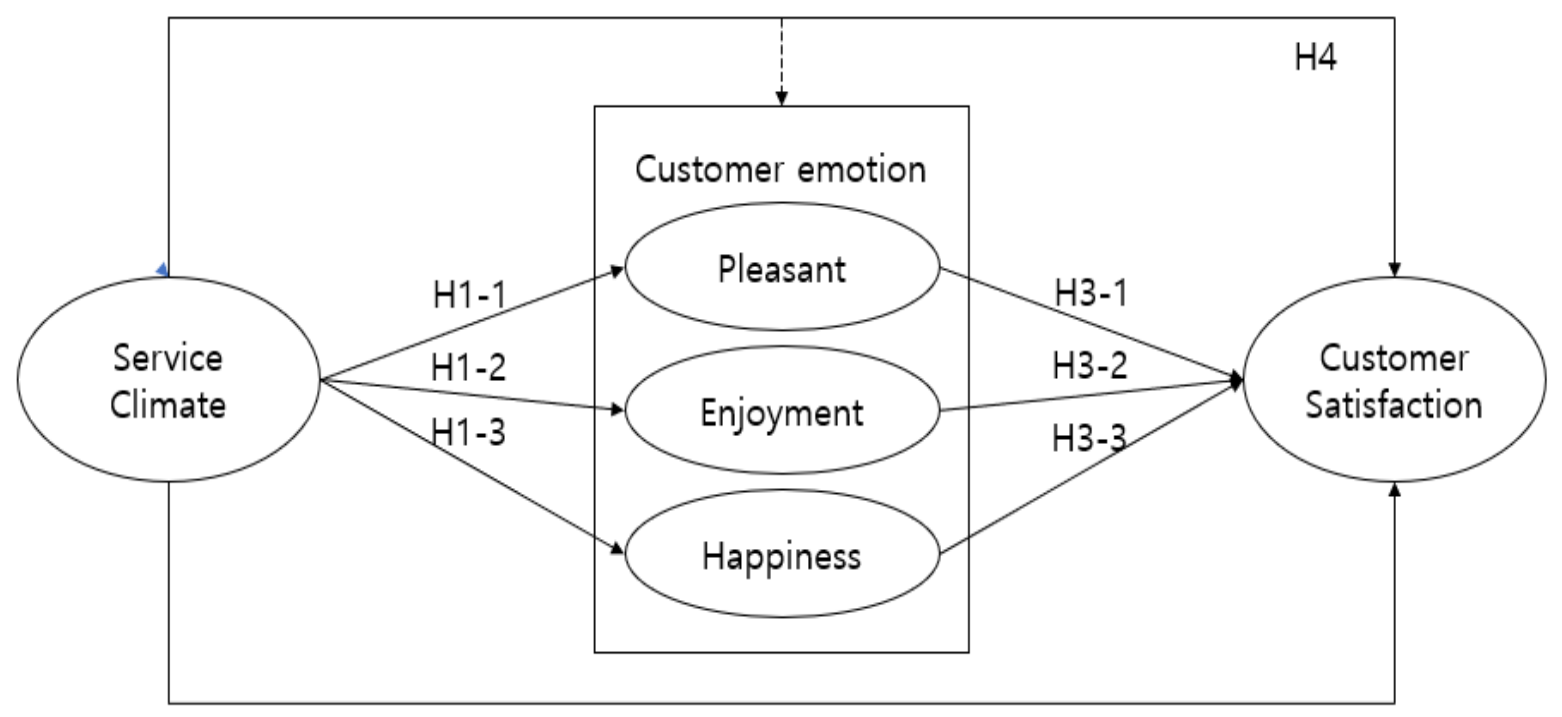

$\mathrm{H} 2$

Figure 1. Research model

\subsubsection{Hypothesis}

H1. Service Climate will have a positive effect on Customer Emotion.

H1-1. Service Climate will have a positive effect on Pleasant.

H1-2. Service Climate will have a positive effect on Enjoyment.

H1-3. Service Climate will have a positive effect on Happiness.

H2. Service Climate will have a positive effect on Customer Satisfaction.

H3. Customer Emotion will have a positive effect on Customer Satisfaction

H3-1. Pleasant will have a positive effect on Customer Satisfaction.

H3-2. Enjoyment will have a positive effect on Customer Satisfaction.

H3-3. Happiness will have a positive effect on Customer Satisfaction.

H4. Customer Emotion will mediate effect between Service Climate and Customer Satisfaction.

H4-1 Pleasant will mediate effect between Service Climate and Customer Satisfaction.

H4-2 Enjoyment will mediate effect between Service Climate and Customer Satisfaction.

H4-3 Happiness will mediate effect between Service Climate and Customer Satisfaction.

\subsubsection{Operational Definition of Variables}

The definition of operation for each variable is summarized as shown in [Table 1] below.

Table 1. Operational Definition of Variables

\begin{tabular}{|c|c|c|c|}
\hline \multicolumn{2}{|c|}{ Latent variables } & Operational Definition & Researcher \\
\hline \multicolumn{2}{|c|}{ Service Climate } & $\begin{array}{l}\text { Refers to the organization's policies, practices and } \\
\text { procedures ensure that employees are aware of the } \\
\text { rewards and expected atmosphere associated with } \\
\text { the quality of the services they provide to } \\
\text { customers. } \\
\text { Behavioral practices and organizational policies that } \\
\text { companies support employees who provide high- } \\
\text { quality services. }\end{array}$ & {$[3],[4]$} \\
\hline \multirow{2}{*}{$\begin{array}{l}\text { Customer } \\
\text { Emotion }\end{array}$} & Pleasant & \multirow{2}{*}{$\begin{array}{l}\text { The emotional and psychological state of the } \\
\text { customer's perception of service communication } \\
\text { and flow. } \\
\text { A behavioral reaction resulting from heightened } \\
\text { physical excitement, according to external stimuli, a } \\
\text { very complex and more comprehensive emotional }\end{array}$} & \multirow{2}{*}{$\begin{array}{l}{[5],[6]} \\
{[11]}\end{array}$} \\
\hline & Enjoyment & & \\
\hline
\end{tabular}




\begin{tabular}{l|l|l|l}
\hline Happiness & $\begin{array}{l}\text { experience, not just pleasure or displeasure, unlike } \\
\text { sentiment. } \\
\text { The level of emotion the customer will experience in } \\
\text { the context of the service interface. }\end{array}$ & $\begin{array}{l}\text { The degree of service the customer expects before } \\
\text { receiving the service and the difference the } \\
\text { customer feels after receiving the service. } \\
\text { Customer satisfaction with employee services }\end{array}$ & [7], [12] \\
\hline
\end{tabular}

\section{Results and Discussion}

\subsection{Empirical Analysis Results}

\subsubsection{Demographic characteristics analysis}

Among the survey respondents in this study, the demographic characteristics of those used in the actual analysis were $55.3 \%$ (136) for males and 44.7\% (110) for females. The highest age group was 50 to $61.0 \%$ (150) and 30 to $19.1 \%$ (47). The highest level of education is $30.5 \%$ (75) for university graduation or above and $34.6 \%$ (85) for high school graduation.

\subsubsection{Descriptive analysis and Exploratory factor analysis}

Descriptive statistical analysis was conducted to confirm the normal distribution of collected data. As a result of the analysis, observation variables SC5 showing extreme values in kurtosis and skewness were removed. An exploratory factor analysis was conducted on the service environment, customer sentiment, and customer satisfaction to test the validity of the variables. As a result of factor analysis, the observation variable EN1and EN2 corresponding to the external load value of less than 0.7 was additionally removed.

\subsubsection{Measurement Model Analysis}

Convergent validity, internal consistency, and discriminant validity tests were performed to test the measurement model. Convergence (concentration) validity is verified based on factor loading and average variance extracted (AVE), and internal consistency is tested by deriving Cronbach's $\alpha$ and complex reliability.

\subsubsection{Internal Consistency and Convergent Validity Analysis}

As a result of convergent validity and internal consistency test, as shown in [Table 2], the factor loading value was above 0.7 , the recommended level, and AVE were above 0.5, the recommended level. Internal consistency was tested by deriving Cronbach's $\alpha$ values and composite reliability. The Cronbach's $\alpha$ values for the latent variables were above the recommended level of 0.7 or higher, and the combined reliability was higher than the recommended level of 0.6 or higher.

Table 2. Results of Measurement Model Analysis

\begin{tabular}{|c|c|c|c|c|c|c|c|}
\hline \multirow{3}{*}{$\begin{array}{l}\text { Latent } \\
\text { Variables }\end{array}$} & \multirow{3}{*}{$\begin{array}{l}\text { Observatio } \\
\text { n Variables }\end{array}$} & \multicolumn{3}{|c|}{ Convergent Validity } & \multicolumn{3}{|c|}{ Internal Consistency Reliability } \\
\hline & & $\begin{array}{l}\text { Factor } \\
\text { Loading }\end{array}$ & $\begin{array}{l}\text { Variable } \\
\text { Reliability }\end{array}$ & AVE & $\begin{array}{l}\text { Cronbach's } \\
\alpha\end{array}$ & $\begin{array}{l}\text { Rho_A } \\
\left(\rho_{A}\right)\end{array}$ & $\begin{array}{l}\text { Composit } \\
\text { e } \\
\text { Reliability }\end{array}$ \\
\hline & & $>.708$ & $>.50$ & $>.50$ & $.60 \sim .90$ & $>.70$ & $.60 \sim .90$ \\
\hline \multirow{5}{*}{$\begin{array}{l}\text { Customer } \\
\text { Satisfaction }\end{array}$} & CS1 & 0.754 & 0.569 & \multirow{5}{*}{.701} & \multirow{5}{*}{.893} & \multirow{5}{*}{.899} & \multirow{5}{*}{.921} \\
\hline & $\mathrm{CS} 2$ & 0.854 & 0.729 & & & & \\
\hline & CS3 & 0.828 & 0.686 & & & & \\
\hline & CS4 & 0.905 & 0.819 & & & & \\
\hline & CS5 & 0.84 & 0.706 & & & & \\
\hline \multirow{2}{*}{ Enjoyment } & EN3 & 0.88 & 0.774 & \multirow{2}{*}{.812} & \multirow{2}{*}{.771} & \multirow{2}{*}{.793} & \multirow{2}{*}{.896} \\
\hline & EN4 & 0.922 & 0.850 & & & & \\
\hline \multirow{4}{*}{ Happiness } & HA1 & 0.816 & 0.666 & \multirow{4}{*}{.719} & \multirow{4}{*}{.870} & \multirow{4}{*}{.872} & \multirow{4}{*}{.911} \\
\hline & HA2 & 0.867 & 0.752 & & & & \\
\hline & HA3 & 0.855 & 0.731 & & & & \\
\hline & HA4 & 0.853 & 0.728 & & & & \\
\hline \multirow{3}{*}{ Pleasant } & PL1 & 0.82 & 0.672 & \multirow{3}{*}{.703} & \multirow{3}{*}{.859} & \multirow{3}{*}{.866} & \multirow{3}{*}{.904} \\
\hline & PL2 & 0.796 & 0.634 & & & & \\
\hline & PL3 & 0.857 & 0.734 & & & & \\
\hline
\end{tabular}




\begin{tabular}{c|l|l|l|l|l|l|l} 
& PL4 & 0.879 & 0.773 & & & & \\
\hline \multirow{3}{*}{$\begin{array}{c}\text { Service } \\
\text { Climate }\end{array}$} & SC1 & 0.845 & 0.714 & & & & \\
\cline { 2 - 4 } & SC2 & 0.872 & 0.760 & \multirow{3}{*}{.730} & .876 & \multirow{3}{*}{.878} & .915 \\
\cline { 2 - 4 } & SC3 & 0.847 & 0.717 & & & & \\
\cline { 2 - 4 } & SC4 & 0.852 & 0.726 & & & & \\
\hline
\end{tabular}

\subsubsection{Discriminant Validity Analysis}

Discriminant validity is verified by comparing the correlation between the square root of the Average variance extraction (AVE) for each variable and other variables, based on Fornell and Larcker's theory. As shown in [Table 3], discriminant validity was secured because the correlation coefficients of all variables were smaller than the AVE square root.

Table 3. Discrimination validity of the measurement model

\begin{tabular}{l|l|l|l|l|l}
\hline Latent Variables & $\begin{array}{l}\text { Customer } \\
\text { Satisfaction }\end{array}$ & Enjoyment & Happiness & Pleasant & $\begin{array}{l}\text { Service } \\
\text { climate }\end{array}$ \\
\hline $\begin{array}{l}\text { Customer } \\
\text { Satisfaction }\end{array}$ & $\mathbf{0 . 8 3 7}$ & & & & \\
\hline Enjoyment & 0.581 & $\mathbf{0 . 9 0 1}$ & & & \\
\hline Happiness & 0.590 & 0.510 & $\mathbf{0 . 8 4 8}$ & & \\
\hline Pleasant & 0.604 & 0.625 & 0.498 & $\mathbf{0 . 8 3 9}$ & \\
\hline $\begin{array}{l}\text { Service } \\
\text { climate }\end{array}$ & 0.673 & 0.581 & 0.508 & 0.657 & $\mathbf{0 . 8 5 4}$ \\
\hline
\end{tabular}

Annotation: The diagonal bold letter is AVE square root.

\subsubsection{Structural Model Analysis}

\subsubsection{Determinant coefficient $\left(R^{2}\right)$ evaluation}

The variance ratio of the endogenous latent variables explained by the exogenous latent variables, that is, the coefficient of determination $\left(\mathrm{R}^{2}\right)$, which means explanatory power, is shown in [Table 4]. Determinants of Happiness Customer Emotion show 25.8\% explanatory power, while those of Customer Satisfaction shows $56.9 \%$ greater explanatory power.

Table 4. Results of Determinant coefficient $\left(R^{2}\right)$ evaluation

\begin{tabular}{l|l|l}
\hline Variables & $\mathrm{R}^{2}$ & Adjusted $\mathrm{R}^{2}$ \\
\hline $\begin{array}{l}\text { Customer } \\
\text { Satisfaction }\end{array}$ & 0.569 & 0.562 \\
\hline Enjoyment & 0.338 & 0.335 \\
\hline Happiness & 0.258 & 0.255 \\
\hline Pleasant & 0.431 & 0.429 \\
\hline
\end{tabular}

\subsubsection{Significance and suitability of path coefficients}

In order to verify this hypothesis, the structural model analysis was analyzed using the bootstrapping of SmartPLS ver.3.3.2. All hypotheses were accepted shown in [Table 5] and the path model was used as shown in [Figure 2] below.

Table 5. Results of Hypothesis test

\begin{tabular}{l|l|l|l|l|l}
\hline Hypothesis Path & $\begin{array}{l}\text { Path } \\
\text { Coefficient }\end{array}$ & $\begin{array}{l}\text { Standard } \\
\text { Deviation }\end{array}$ & $\begin{array}{l}\text { t- } \\
\text { value }\end{array}$ & $\begin{array}{l}\text { p- } \\
\text { value }\end{array}$ & Result \\
\hline Enjoyment -> Customer Satisfaction & 0.149 & 0.066 & 2.262 & 0.024 & Accept \\
\hline Happiness -> Customer Satisfaction & 0.259 & 0.065 & 3.980 & 0.000 & Accept \\
\hline Pleasant -> Customer Satisfaction & 0.147 & 0.067 & 2.204 & 0.028 & Accept \\
\hline
\end{tabular}




\begin{tabular}{l|l|l|l|l|l|l} 
Service climate -> Customer Satisfaction & 0.358 & 0.068 & 5.295 & 0.000 & Accept \\
\hline Service climate -> Enjoyment & 0.581 & 0.047 & 12.464 & 0.000 & Accept \\
\hline Service climate -> Happiness & 0.508 & 0.049 & 10.430 & 0.000 & Accept \\
\hline Service climate -> Pleasant & 0.657 & 0.045 & 14.653 & 0.000 & Accept \\
\hline
\end{tabular}

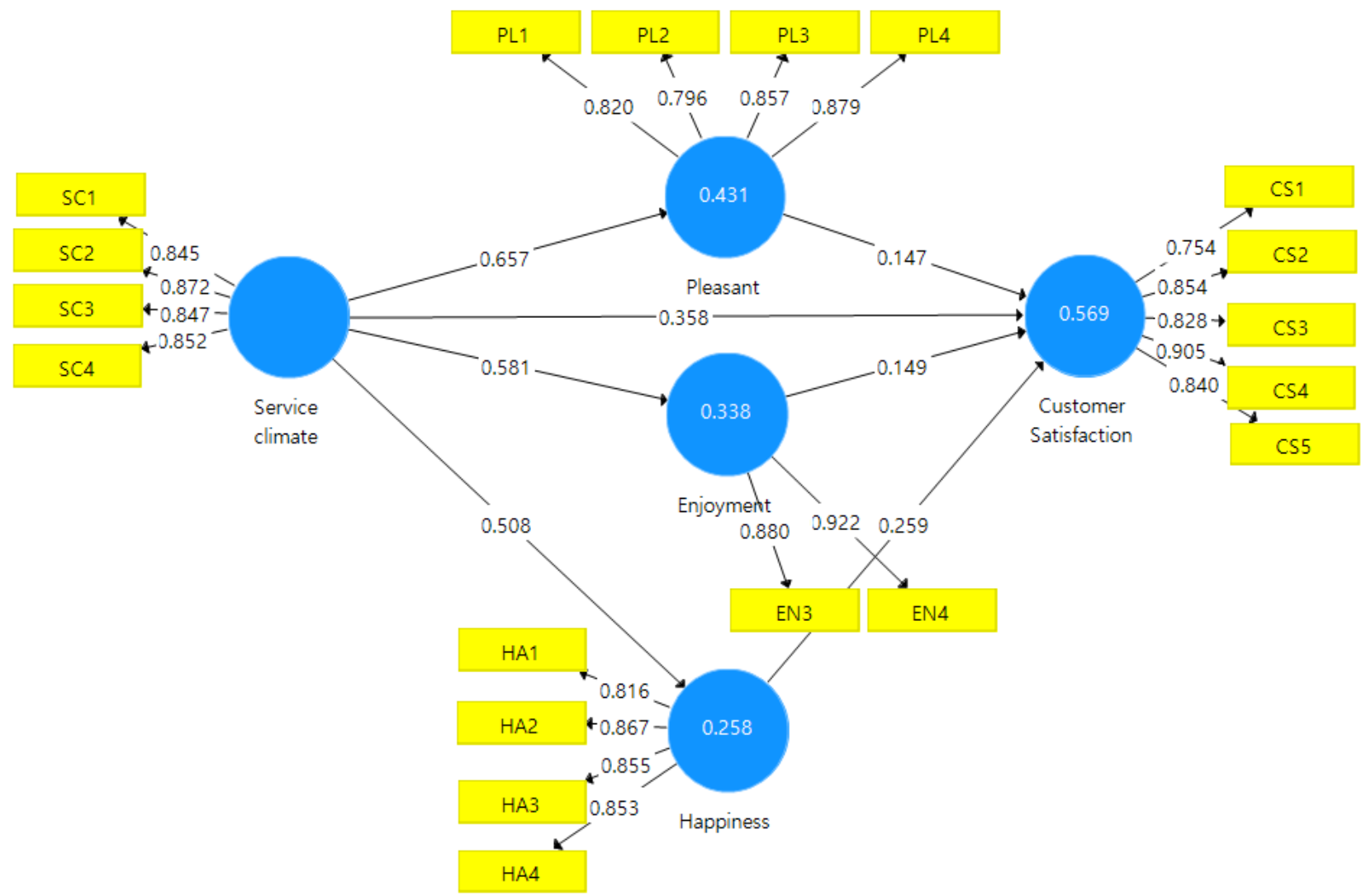

Figure 2. Path Coefficient Analysis

\subsubsection{Mediating Effect Analysis}

As shown in [Table 6], the coordination effect of customer emotion was significant and most hypotheses were accepted as a result of the verification of arbitration effect by specific indirect effects analysis to verify the coordination effect of customer emotion in the relationship between the service climate and customer satisfaction.

Table 6. Result of Mediating effect analysis

\begin{tabular}{l|l|l|l|l|l}
\hline Hypothesis Path & $\begin{array}{l}\text { Path } \\
\text { Coefficient }\end{array}$ & $\begin{array}{l}\text { Standard } \\
\text { Deviation }\end{array}$ & t-value & p-value & Result \\
\hline $\begin{array}{l}\text { Service Climate > Enjoyment -> } \\
\text { Customer Satisfaction }\end{array}$ & 0.087 & 0.038 & 2.259 & 0.024 & Accept \\
\hline $\begin{array}{l}\text { Service Climate - Happiness -> } \\
\text { Customer Satisfaction }\end{array}$ & 0.131 & 0.036 & 3.616 & 0.000 & Accept \\
\hline $\begin{array}{l}\text { Service Climate -> Pleasant -> } \\
\text { Customer Satisfaction }\end{array}$ & 0.096 & 0.045 & 2.123 & 0.034 & Accept \\
\hline
\end{tabular}

\section{Conclusion}

This study was intended to use it as a basic data to explore ways to strengthen the competitiveness of the restaurant business by analyzing the impact of service climate on customer sentiment and customer satisfaction. Looking at the results of the study, the first company's service climate affects all positive customer emotion: pleasantness, pleasure and happiness. Establishing a corporate service climate has been confirmed to be an important factor in positive customer emotion. Second, the corporate service 
climate has a positive impact on customer satisfaction. Recognizing that the perceived organizational culture that employees have in common is an important factor in customer satisfaction can create a stronger service climate and develop into higher customer satisfaction. Third, positive customer sentiment affects customer satisfaction. Fourth, when the service climate of the company affects customer satisfaction, the positive customer emotion, pleasant, enjoyment, and happiness, played a mediating role, and the independent variables were all partially mediated. Among them, happiness appeared to be the most influential factor, showing that it is important to satisfy the customer's happy feelings when the service climate affects customer satisfaction. In order to satisfy customers through research results, establishing and utilizing service climate is important, and since customer's happiness affects service climate and satisfaction, continuous measures to satisfy customer's happiness should be developed. To improve customer satisfaction, it will be necessary to give employees the authority and responsibility to make decisions on their own, so that they are positively aware of the service climate. It is necessary to emphasize the importance of the service climate because the higher the service climate, the higher the customer's emotional response, the higher the customer's positive response, and the higher the customer's satisfaction. Therefore, in this study, establishing a service climate for employees working in restaurant businesses is of paramount importance in the service interface with customers, and if the service climate has made the customer highly aware of positive feelings in the service interaction process, this customer will be able to appreciate the satisfaction. Therefore, restaurant business will build positive loyalty or reduce customer churn in the future. The results of this study will be insufficient to apply to the overall enterprise because the study was conducted on some restaurant businesses due to time and economic limitations. In this study, the relationship between service climate, customer sentiment, and customer satisfaction. A study that recognizes changes in customer sentiment and satisfaction in consideration of changes in service climate components following the recent development of the fourth industry could produce more meaningful research results.

\section{Acknowledgment}

This research was financially supported by Hansung University.

\section{References (Chicago)}

[1] Bowen, David E., and Benjamin Schneider. "Services marketing and management-implications for organizational-behavior." Research in organizational behavior 10 (1988): 43-80.

[2] Anderson, Eugene W., Claes Fornell, and Donald R. Lehmann. "Customer satisfaction, market share, and profitability: Findings from Sweden." Journal of marketing 58, no. 3 (1994): 53-66.

[3] Schneider, Benjamin. "The climate for service: An application of the climate construct." Organizational climate and culture 1 (1990): 383-412.

[4] Schneider, Benjamin, and David E. Bowen. "Employee and customer perceptions of service in banks: Replication and extension." Journal of applied Psychology 70, no. 3 (1985): 423.

[5] Bergenwall, Maria. An overview of emotion theory: Incorporating the concept of emotion into service quality research. Swedish School of Economics and Business Administration, 1998.

[6] Kim, J. Y., Y. N. Lee, and T. H. Kim. "The influence of physical surroundings and human services on emotional responses and behavioral intentions of theme restaurant customers." International Journal of Tourism and Hospitality Research 21, no. 2 (2007): 91-107.

[7] Garvin, David A. "Product quality: An important strategic weapon." Business horizons 27, no. 3 (1984): 40-43.

[8] Rust, Roland T., and Richard L. Oliver. "Should we delight the customer?" Journal of the Academy of Marketing Science 28, no. 1 (2000): 86.

[9] Gardner, Meryl Paula. "Mood states and consumer behavior: A critical review." Journal of Consumer research 12, no. 3 (1985): 281-300.

[10] Jung, Hyo-Sun, and Hye-Hyun Yoon. "The effect of physical environment of family restaurant upon customers' emotions, satisfaction and revisit intent-Focused on the moderating roles of gender and age." Culinary science and hospitality research 16, no. 4 (2010): 190-205.

[11] Hennig-Thurau, Thorsten, Markus Groth, Michael Paul, and Dwayne D. Gremler. "Are all smiles created equal? How emotional contagion and emotional labor affect service relationships." Journal of Marketing 70, no. 3 (2006): 58-73.

[12] Fornell, Claes, Michael D. Johnson, Eugene W. Anderson, Jaesung Cha, and Barbara Everitt Bryant. "The American customer satisfaction index: nature, purpose, and findings." Journal of marketing 60, no. 4 (1996): 7-18.

[13] Dietz, Joerg, S. Douglas Pugh, and Jack W. Wiley. "Service climate effects on customer attitudes: An examination of boundary conditions." Academy of management journal 47, no. 1 (2004): 81-92. 